\title{
Changing the dress to a MOF through perfluorination and transmetallation. Structural and Gas-Sorption Effects
}

Davide Balestri ${ }^{\dagger}$, Irene Bassanetti ${ }^{\ddagger}$,Stefano Canossa ${ }^{\dagger,}$, , Cristina Gazzurelli ${ }^{\dagger}$, Alessia Bacchi ${ }^{\dagger}$, Silvia Bracco ${ }^{\ddagger}$, Angiolina Comotti ${ }^{\ddagger}$ Paolo Pelagatti ${ }^{\dagger, \# *}$

$\dagger$ Department of Chemical Sciences, Life Sciences and Environmental Sustainability, University of Parma, Viale delle Scienze, 17A, 43124, Parma, Italy.

+ Department of Materials Science, University of Milano-Bicocca, via Roberto Cozzi, 55, 20125 Milano, Italy.

\# Interuniversity Consortium Chemical Reactivity and Catalysis (CIRCC), Via Celso Ulpiani 27, 70126, Bari, Italy

KEYWORDS Metal-Organic Framework; pillar; transmetallation; carbon dioxide uptake; amide linker; fluorinated linker

ABSTRACT Two novel pillared Zn(II)-based Metal-Organic Frameworks were de-novo synthesized exploiting $N, N^{\prime}-\left(1,1^{\prime}\right.$-biphenyl)-4,4'-diylbis-4-pyridinecarboxamide (bpba) and its fluorinated analogous $N, N^{\prime}$-(perfluoro-1,1'-biphenyl-4,4'-diyl)diisonicotinamide (F-bpba) as suitable pillar linkers and 2,6-naphthalene dicarboxylic acid as carboxylic ligand. The resulting

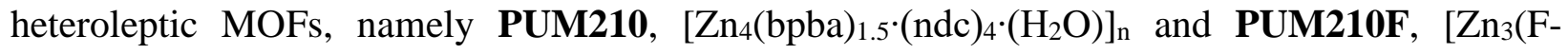
bpba) $\left.)_{1}(\mathrm{ndc})_{3} \cdot(\mathrm{DMF})\right]_{\mathrm{n}}$, feature an uncommon truncation of the $\mathrm{Zn}(\mathrm{II})$ paddle-wheel nodes along 
the pillaring direction. PUM210 and PUM210F exhibit a polycatenated architecture, resulting in microporous channels decorated by amide moieties. The activated forms show a permanent porosity and a selective adsorption of $\mathrm{CO}_{2}$ over $\mathrm{N}_{2}$. Moreover, the partially transmetallated $\mathbf{C u}-$ PUM210 and Cu-PUM210F were obtained by convenient transmetallation protocol and their adsorption propriety towards $\mathrm{CO}_{2}$ were subsequently investigated.

\section{INTRODUCTION}

Among porous materials, Metal-Organic Frameworks (MOFs) are well-known for the high versatility of their structural design and tailoring. ${ }^{1,2}$ This comes from the possibility of selecting the most appropriate ligands and metal nodes to reach the desired architecture, which can be further tuned by post-synthetic modifications (PSM). Among the most effective PSM protocols, transmetallation, ${ }^{3}$ i.e. the replacement of framework metal ions, is of particular interest, because it can have profound effects not only on the final crystalline structure, in some occasions leading to the isolation of solid phases not obtainable under conventional synthetic protocols, ${ }^{4-6}$ but even on framework stability, ${ }^{7}$ porosity and then uptake properties. ${ }^{8}$ In particular, the selectivity towards $\mathrm{CO}_{2}$ trapping is of paramount relevance, owing to the dramatic environmental issues linked to this greenhouse gas. ${ }^{9-11}$ Significant enhancements of both carbon dioxide uptake and selectivity have been reached exploiting the quadrupolar moment of $\mathrm{CO}_{2 \cdot}{ }^{12,13}$ Hence, a wide applied protocol regards the introduction of polar groups, such as amine ${ }^{14-16}$ or amide, ${ }^{17,18}$ in the MOF framework to strengthen the interactions between $\mathrm{CO}_{2}$ molecules and the MOF internal walls. In particular, amide groups can interact with carbon dioxide through $\mathrm{N}-\mathrm{H} \ldots \mathrm{O}=\mathrm{CO}$ hydrogen-bonds or act as Lewis base through N...CO contacts. ${ }^{19-21}$ Another successful strategy which can be exploited for the preparation of good sorbents is based on perfluorination or partial 
fluorination of organic linkers. Although a favorable effect is not easily predictable a priori, in some cases significant enhancements of carbon dioxide trapping have been observed. ${ }^{22-25}$

Starting from these considerations, we decided to employ the two amide-containing ligands $N, N^{\prime}$-(1,1'-biphenyl)-4,4'-diylbis-4-pyridinecarboxamide (bpba) and its fluorinated analogous $N, N^{\prime}$-(perfluoro-1,1'-biphenyl-4,4'-diyl)diisonicotinamide (F-bpba) for the self-assembly of novel pillared $\mathrm{MOFs}^{26}$ (Scheme 1). The two ligands have the same length and then are expected, once combined with the same di-carboxylate ligand and the same SBU, to lead to structurally very similar pillared MOFs. However, the perfluorinated biphenyl core of F-bpba allows to evaluate the effect of perfluorination on the carbon dioxide uptake. To the best of our knowledge, bpba has rarely been used for the construction of metal-containing assemblies, ${ }^{27}$ while its use in MOF synthesis has been recently reported by us. ${ }^{28} \mathbf{F}$-bpba is a new bis-pyridine ligand never reported in literature.

The two ligands were used to assemble two new heteroleptic pillared MOFs, $\left[\mathrm{Zn}_{4}(\mathrm{bpba})_{1.5} \cdot(\mathrm{ndc})_{4} \cdot\left(\mathrm{H}_{2} \mathrm{O}\right)\right]_{\mathrm{n}}(\mathbf{P U M 2 1 0})$ and $\left[\mathrm{Zn}_{3}(\mathrm{~F}-\mathrm{bpba})_{1} \cdot(\mathrm{ndc})_{3} \cdot(\mathrm{DMF})\right]_{\mathrm{n}}(\mathbf{P U M 2 1 0 F})(\mathrm{PUM}$ stands for Parma University Materials), which were structurally characterized by single crystal X-ray analysis. Moreover, the corresponding partially transmetallated $\mathrm{Cu}-\mathrm{MOFs}$ were obtained through a mild transmetallation protocol yielding to the heterometallic $\mathrm{Zn}^{2+}-\mathrm{Cu}^{2+}$ materials $\mathbf{C u}$ PUM210 and Cu-PUM210F. In this work the structural differences arising from perfluorination and transmetallation will then be discussed, together with the sorption properties of the isolated crystalline materials towards $\mathrm{CO}_{2}, \mathrm{~N}_{2}$ and $\mathrm{CH}_{4}$, with particular regard to the $\mathrm{CO}_{2}$ selective adsorption. 


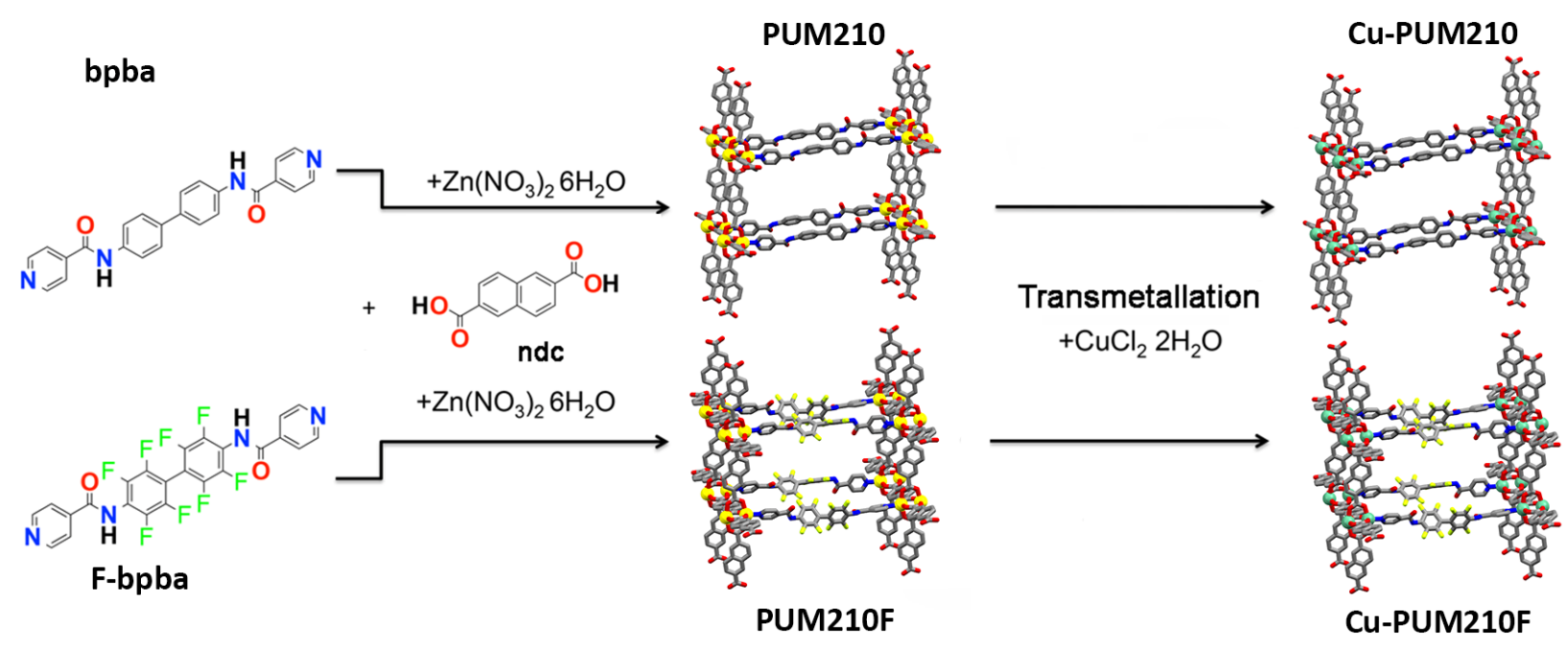

Scheme1. Schematic representation of the synthesis of the MOFs shown in this work

\section{EXPERIMENTAL SECTION}

Materials and Methods: The ligand N,N'-(1,1'-biphenyl)-4,4'-diylbis-4-pyridinecarboxamide (bpba) was synthesized according to the previously published Pd-catalyzed cross-coupling protocol optimized in our laboratory. ${ }^{29} N, N^{\prime}$-(perfluoro-1,1'-biphenyl-4,4'-diyl)diisonicotinamide (F-bpba) was synthesized according to the procedure described below. 2,6naphthalendicarboxylic acid (ndc) and all other reagents and solvents are commercially available and were used as received.

Physical and Chemical Measurements. The details of the apparatus used for the spectroscopic and thermal characterization are given in the Supporting Information.

Single Crystal X-ray Crystallography (SC-XRD): Crystal measurements were performed at Elettra Syncrotron (Trieste, Italy) on beamline XRD1 at 100K under cold nitrogen flux. ${ }^{30}$ The source used for the analysis was a NdBFe Multipole Wiggler (Hybrid linear), $4.27 \mathrm{KeV}$ with a power of $8.6 \mathrm{~kW}$, a source size FWHM of $2.0 \times 0.37 \mathrm{~mm}(0.7 \times 0.2 \mathrm{~mm}$ FWHM beam size at sample) and photon flux 1012-1013 ph/sec. MOFs crystals were taken from the mother liquor or washing DMF and mounted with cryoloops $(0.05-0.3 \mathrm{~mm})$, prior a flash freezing at $100 \mathrm{~K}$. 
Diffraction data were indexed, integrated, and scaled using CrysAlis software. Structures were solved by direct methods using SHELXS ${ }^{31}$ and refined by full-matrix least-squares on all F2 using SHELXL implemented in Olex2. ${ }^{32}$ For all the structures, anisotropic displacement parameters were refined except for hydrogen atoms. Unstructured residual electron density found inside cavities was accounted for by the Mask procedure in Olex. Table 1 reports the results of crystal structures determination. Crystallographic data for PUM210, PUM210F, and CuPUM210F have been deposited with the Cambridge Crystallographic Data Centre (18494571849459) .

Table 1. Crystal data and structural refinement.

\begin{tabular}{|c|c|c|c|}
\hline & PUM210 & PUM210F & Cu-PUM210F \\
\hline Empirical formula & $\mathrm{C}_{186} \mathrm{H}_{148} \mathrm{~N}_{18} \mathrm{O}_{46} \mathrm{Zn}_{8}$ & $\mathrm{C}_{63} \mathrm{H}_{35} \mathrm{~F}_{8} \mathrm{~N}_{5} \mathrm{O}_{15} \mathrm{Zn}_{3}$ & $\mathrm{C}_{72} \mathrm{H}_{56} \mathrm{Cu}_{3} \mathrm{~F}_{8} \mathrm{~N}_{8} \mathrm{O}_{18}$ \\
\hline Formula weight & 3894.18 & 1450.07 & 1663.86 \\
\hline Temperature/K & 100.0 & 100.0 & 100.0 \\
\hline Crystal system & monoclinic & monoclinic & monoclinic \\
\hline Space group & $\mathrm{C} 2 / \mathrm{c}$ & $\mathrm{P} 21 / \mathrm{c}$ & $\mathrm{P} 21 / \mathrm{c}$ \\
\hline $\mathrm{a} / \AA$ & $18.9998(6)$ & $31.7870(4)$ & $31.6781(17)$ \\
\hline $\mathrm{b} / \AA$ & $18.0175(5)$ & $17.3848(2)$ & $17.4634(4)$ \\
\hline $\mathrm{c} / \AA$ & $62.1271(16)$ & $19.5421(3)$ & $19.4796(7)$ \\
\hline$\alpha /{ }^{\circ}$ & 90 & 90 & 90 \\
\hline$\beta /{ }^{\circ}$ & $90.557(2)$ & $97.3440(10)$ & $97.172(3)$ \\
\hline$\gamma /{ }^{\circ}$ & 90 & 90 & 90 \\
\hline Volume $/ \AA^{3}$ & $21266.9(10)$ & $10710.6(2)$ & $10691.9(7)$ \\
\hline $\mathrm{Z}$ & 4 & 4 & 4 \\
\hline pcalcg/cm 3 & 1.216 & 0.899 & 1.034 \\
\hline $\mathrm{F}(000)$ & 7992.0 & 2920.0 & 3388.0 \\
\hline $\begin{array}{l}2 \Theta \text { range for data } \\
\text { collection }^{\circ}\end{array}$ & 3.32 to 51.888 & 3.1 to 57.298 & 3.446 to 51.888 \\
\hline Index ranges & $\begin{array}{l}-23 \leq \mathrm{h} \leq 23,-20 \leq \mathrm{k} \leq \\
20,-74 \leq 1 \leq 76\end{array}$ & $\begin{array}{l}-43 \leq \mathrm{h} \leq 43,-23 \leq \mathrm{k} \\
\leq 23,-26 \leq 1 \leq 26\end{array}$ & $\begin{array}{l}-37 \leq \mathrm{h} \leq 39,-21 \leq \mathrm{k} \leq 21 \\
-23 \leq 1 \leq 23\end{array}$ \\
\hline Reflections collected & 57163 & 175080 & 44236 \\
\hline Independent reflections & $\begin{array}{l}21249[\text { Rint }=0.0748, \\
\text { Rsigma }=0.0589]\end{array}$ & $\begin{array}{l}28514[\text { Rint }=0.0505, \\
\text { Rsigma }=0.0240]\end{array}$ & $\begin{array}{l}20826[\text { Rint }=0.0504, \\
\text { Rsigma }=0.0579]\end{array}$ \\
\hline Data/restraints/parameters & $21249 / 636 / 1084$ & $28514 / 517 / 1098$ & $20826 / 301 / 1431$ \\
\hline Goodness-of-fit on F2 & 2.725 & 1.062 & 1.429 \\
\hline Final $R$ indexes $[I>=2 \sigma(I)]$ & $\begin{array}{l}\mathrm{R} 1=0.2301, \mathrm{wR} 2= \\
0.5843\end{array}$ & $\begin{array}{l}\mathrm{R} 1=0.0638, \mathrm{wR} 2= \\
0.2089\end{array}$ & $\begin{array}{l}\mathrm{R} 1=0.1045, \mathrm{wR} 2= \\
0.3472\end{array}$ \\
\hline Final $\mathrm{R}$ indexes [all data] & $\begin{array}{l}\mathrm{R} 1=0.2437, \mathrm{wR} 2= \\
0.5923\end{array}$ & $\begin{array}{l}\mathrm{R} 1=0.0702, \mathrm{wR} 2= \\
0.2165\end{array}$ & $\begin{array}{l}\mathrm{R} 1=0.1188, \mathrm{wR} 2= \\
0.3615\end{array}$ \\
\hline
\end{tabular}


Synthesis of $\boldsymbol{F}$-bpba. In a $250 \mathrm{~mL}$ two neck round bottomed flask, octafluorobenzidine $(0.50 \mathrm{~g}$, $1.52 \mathrm{mmol})$, triethylamine $(1.0 \mathrm{~mL}, 7.30 \mathrm{mmol}, 4.8$ equivalents $)$ and isonicotinoyl chloride hydrochloride ( $0.65 \mathrm{~g}, 3.65 \mathrm{mmol}, 2.4$ equivalents) were added to dry toluene $(30 \mathrm{~mL})$. The resulting reaction mixture was heated at reflux for 5 days. Then, water $(30 \mathrm{~mL})$ was added and the crude was isolated by vacuum filtration. The resulting off-white solid was washed with water $(3 \times 10 \mathrm{~mL})$ and ethanol and dried to provide F-bpba $(0.61 \mathrm{~g}, 1.12 \mathrm{mmol}, \mathrm{y}=74 \%) .{ }^{1} \mathrm{H}-\mathrm{NMR}$ $\left(400 \mathrm{MHz}, \mathrm{DMSO}-\mathrm{d}^{6}, 25^{\circ} \mathrm{C}\right) \delta: 11.19(\mathrm{~s}, 2 \mathrm{H}, \mathrm{NH}), 8.87\left(\mathrm{~d}, J=5.6 \mathrm{~Hz}, 4 \mathrm{H}, \mathrm{CH}_{\mathrm{pyr}}\right), 7.94(\mathrm{~d}, J=$ $\left.5.6 \mathrm{~Hz}, 4 \mathrm{H}, \mathrm{CH}_{\text {pyr }}\right)$ ppm; ${ }^{19} \mathrm{~F}\left\{{ }^{1} \mathrm{H}\right\}-\mathrm{NMR}\left(377 \mathrm{MHz}, \mathrm{DMSO}-\mathrm{d}^{6}, 25^{\circ} \mathrm{C}\right) \delta:-139.12(\mathrm{~m}),-143.43$ (m) ppm; ${ }^{13} \mathrm{C}\left\{{ }^{1} \mathrm{H}\right\}-\mathrm{NMR}\left(100 \mathrm{MHz}, \mathrm{DMSO}-\mathrm{d}^{6}, 25^{\circ} \mathrm{C}\right): 164.6(\mathrm{C}=\mathrm{O}), 151.1(\mathrm{CH}), 144.2$ (dd, $\left.{ }^{1} J_{\mathrm{CF}}=251.0 \mathrm{~Hz},{ }^{2} J_{\mathrm{CF}}=14.0 \mathrm{~Hz}, \mathrm{CF}\right), 142.5\left(\mathrm{dd},{ }^{1} J_{\mathrm{CF}}=251.0 \mathrm{~Hz},{ }^{2} J_{\mathrm{CF}}=14.0 \mathrm{~Hz}, \mathrm{CF}\right), 139.8(\mathrm{C}-$ $\mathrm{C}=\mathrm{O}$ ), $112.3(\mathrm{CH}), 119.8$ (m, C-N ipso), 104.5 (m, C-CF ipso) ppm; IR (ATR, $\mathrm{cm}^{-1}$ ): 3235, 1687, 1516, 1496, 1468, 1413, 1299, 987, 915, 845, 759, 737, 728, 711, 670, 654, 618; MS (ESI $+): \mathrm{m} / \mathrm{z} 539.1[\mathrm{M}+\mathrm{H}]^{+}$.

Synthesis of PUM210: In a $70 \mathrm{~mL}$ pyrex glass tube, bpba (0.2 mmol, $80 \mathrm{mg})$, 2,6naphthalendicarboxylic acid $(0.4 \mathrm{mmol}, 86 \mathrm{mg})$ and $\mathrm{Zn}\left(\mathrm{NO}_{3}\right)_{2} \cdot 6 \mathrm{H}_{2} \mathrm{O}(0.4 \mathrm{mmol}, 120 \mathrm{mg})$ were added to DMF (41 mL). The resulting mixture was sonicated, then heated under autogenous pressure at $80^{\circ} \mathrm{C}$. After 5 days the reaction vessel was slowly cooled to room temperature. The resulting small yellow crystals were washed with DMF $(2 \times 10 \mathrm{~mL})$.

Synthesis of PUM210F: In a $20 \mathrm{~mL}$ pyrex glass tube, F-bpba (0.1 mmol, $54 \mathrm{mg}), 2,6-$ naphthalendicarboxylic acid $(0.2 \mathrm{mmol}, 40 \mathrm{mg})$ and $\mathrm{Zn}\left(\mathrm{NO}_{3}\right)_{2} \cdot 6 \mathrm{H}_{2} \mathrm{O}(0.2 \mathrm{mmol}, 60 \mathrm{mg})$ were added to DMF (10 mL). The resulting mixture was sonicated, then heated under autogenous 
pressure at $80^{\circ} \mathrm{C}$. After 5 days, the reaction vessel was slowly cooled to room temperature. The resulting colourless small crystals were washed with DMF (2 x $10 \mathrm{~mL})$.

Transmetallation reactions: Single crystals of PUM210 and PUM210F were dipped in DMF for 2 days to dissolve any remaining side products that may have been adhered to the crystals. Then, the crystals were soaked in a $\mathrm{CuCl}_{2} 0.01 \mathrm{M}$ DMF solution at $60^{\circ} \mathrm{C}$ for at least three days to obtain the $\mathrm{Cu}$-containing phase. During the transmetallation process the $\mathrm{Cu}$-containing solution was refreshed each 24/48 hours. The occurring of the reaction could be appreciated by naked eye, since the yellow crystals of PUM210 turned green (Cu-PUM210) while the white crystals of PUM210F turned turquois (Cu-PUM210F). Copper-content was determined by ICP-OES analysis.

\section{RESULTS AND DISCUSSION}

Synthesis and Comparative Analysis of the Crystal Structures of PUM210 and PUM210F. The solvothermal reaction of bpba, ndc and $\mathrm{Zn}\left(\mathrm{NO}_{3}\right)_{2} \cdot 6 \mathrm{H}_{2} \mathrm{O}$ in a 2:1:2 molar ratio in DMF at $80{ }^{\circ} \mathrm{C}$ provided PUM210 as yellow plate crystals. The same reaction conditions were successfully applied to the synthesis of PUM210F but replacing bpba with F-bpba. The perfluorinated network was isolated as colourless plate crystals. The solid state structures of PUM210 and PUM210F were determined by single-crystal X-ray analysis performed with synchrotron light radiation. 


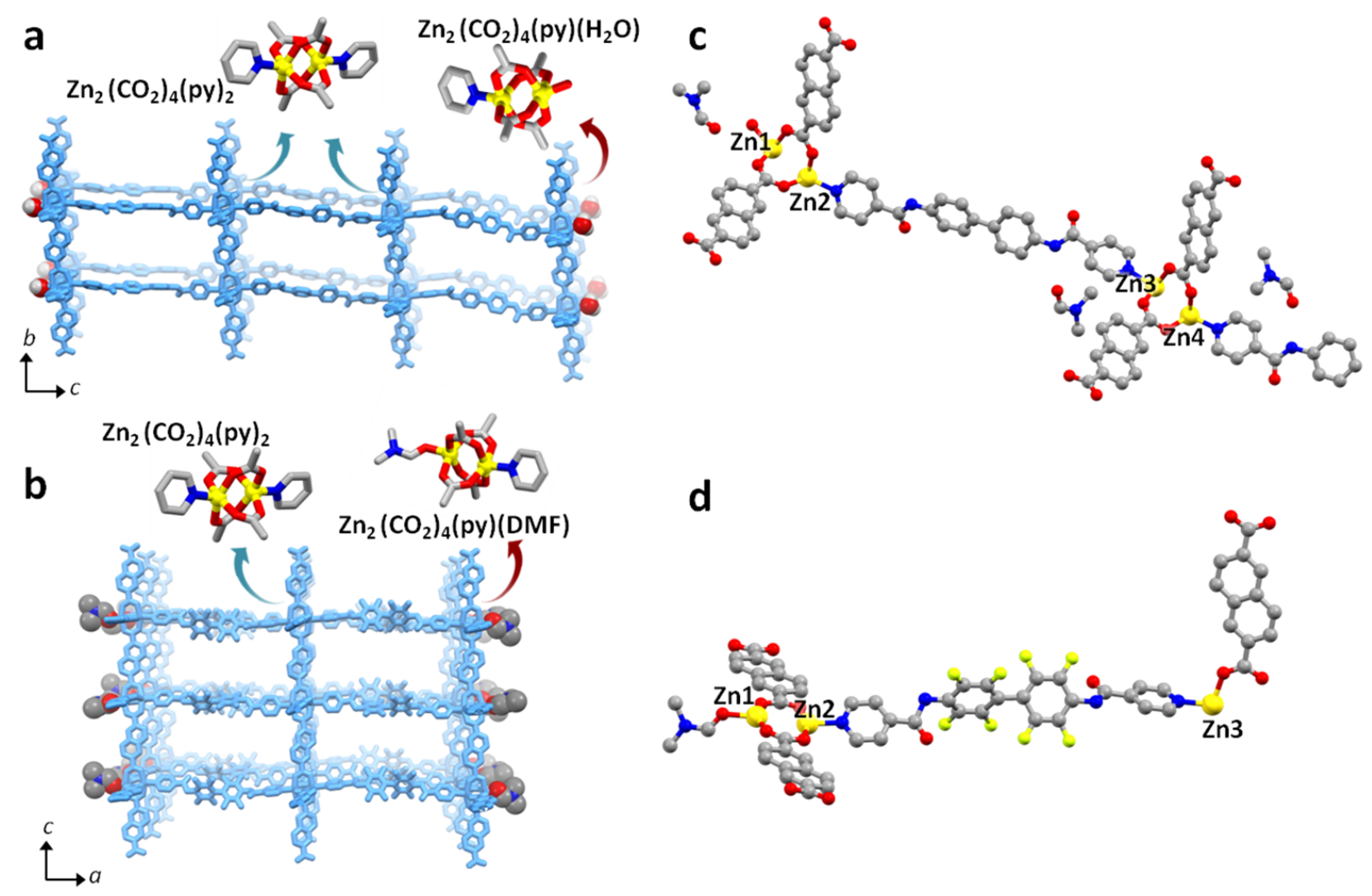

Figure 1. Framework architectures and SBUs found in PUM210 (a) and PUM210F (b); (c) detail of PUM210 (c) and PUM210F (d) asymmetric units.

PUM210 crystallizes in the monoclinic C2/c space group. The asymmetric unit consists of four independent $\mathrm{Zn}^{2+}$ cations, one and a half bpba ligand, four $\mathrm{ndc}^{2-}$ anions and three modelled DMF molecules (Figure 1c). Residual electron density (340 electrons inside each of two residual cavities of $2760 \AA^{3}$ ) indicates the presence of around 8 additional DMF molecules per cavity which were not possible to model. Its whole formula is then $\left[\mathrm{Zn}_{4}(\mathrm{bpba})_{1.5^{\circ}} \cdot(\mathrm{ndc})_{4} \cdot\left(\mathrm{H}_{2} \mathrm{O}\right)\right]_{\mathrm{n}} \cdot(\mathrm{DMF})_{\mathrm{x}}$. The ${ }^{1} \mathrm{H}-\mathrm{NMR}$ spectrum recorded on native crystals dissolved in a TFA-d/DMSO-d mixture indicates the presence of 4-5 molecules of DMF (see Figure S14), hence part of the included DMF was likely removed by vacuum drying prior to NMR analysis. 
Notably, PUM210 shows two different types of $\mathrm{Zn}_{2}$ paddle-wheel SBUs. ${ }^{33} \mathrm{Zn} 3$ and $\mathrm{Zn} 4$ form the classical $\left[\mathrm{Zn}_{2}(\mathrm{COO})_{4}(\mathrm{py})_{2}\right]$ unit (indicated with blue arrows in Figure 1a), where the metals lie in a square pyramidal coordination environment ensured by four bridging carboxylates and two pyridine moieties. Each SBU of this type is bridged by a bpba ligand oriented along $c$ axis to a second type of SBU, which is a truncated paddle-wheel of the type $\left[\mathrm{Zn}_{2}(\mathrm{COO})_{4}(\mathrm{py})\left(\mathrm{H}_{2} \mathrm{O}\right)\right]$ containing $\mathrm{Zn} 1$ and $\mathrm{Zn} 2$ (indicated with red arrow in Figure 1a). Here the truncation of the SBU is due to a molecule of water which occupies the position where a pyridine moiety was expected to be found. It is noteworthy commenting that only very few examples of truncated $\mathrm{Zn}$-paddlewheels are reported in literature. ${ }^{34-36}$ As shown in Figure 1a, the combination of these two SBUs generates 2D sheets forming an infinite polymeric expansion along the $a$ and $b$ directions, which form the plane where the carboxylate square grids lie. Instead, along $c$ direction, the truncation of the $\mathrm{Zn}$ paddle wheel leads to an interruption of the pillar motif, which is therefore limited to three bpba units. The coordinated water is also involved in a hydrogen bond interaction with a DMF solvent molecule (Figure 1c).

The crystallographic analysis conducted on PUM210F reveals that it crystallizes in the monoclinic P2 $1 / \mathrm{c}$ space group. The asymmetric unit (Figure 1d) contains three independent $\mathrm{Zn}^{2+}$ cations, three ndc ${ }^{2-}$ anions, one F-bpba ligand, disordered on two positions (see Supporting Info, Fig S20) and one modelled DMF molecule coordinated to Zn1 (Figure 1d). Residual electron density (1300 electrons in a void volume of $\left.5530 \AA^{3}\right)$ indicates the presence of around 32 additional disordered molecules of DMF in the cell. Its whole formula is then $\left[\mathrm{Zn}_{3}(\mathbf{F}\right.$ bpba) $\left.)_{1} \cdot(\mathrm{ndc})_{3} \cdot(\mathrm{DMF})\right]_{\mathrm{n}} \cdot(\mathrm{DMF})_{\mathrm{x}} \cdot{ }^{1} \mathrm{H}-\mathrm{NMR}$ spectroscopy conducted on native crystals digested in a TFA-d/DMSO-d mixture (see Figure S14) indicates the presence of 2.5 molecules of DMF. Again, most of the DMF molecules have likely been removed by vacuum prior to NMR analysis. 
Analogously to PUM210, the structural motif shows again the two different $\mathrm{Zn}_{2}$ paddle-wheel units (Figure 1c), one integral comprising $\mathrm{Zn} 3$ of the type $\left[\mathrm{Zn}_{2}(\mathrm{COO})_{4}(\mathrm{py})_{2}\right]$, and one truncated comprising $\mathrm{Zn} 1$ and $\mathrm{Zn} 2$ of the type $\left[\mathrm{Zn}_{2}(\mathrm{COO})_{4}(\mathrm{py})(\mathrm{DMF})\right]$. The different composition of the truncated SBU found in PUM210 and PUM210F reflects the higher hydrophobicity expected for the perfluorinated MOF. As regard the coordination environment of the metal ions, $\mathrm{Zn} 1$ is bound to four carboxylic oxygens of four different $n \mathrm{nd}^{2-}$ anions and one oxygen belonging to a DMF molecule, whereas $\mathrm{Zn} 2$ is bound to four carboxylic oxygens of four different $\mathrm{ndc}^{2-}$ anions and one pyridine ring of a F-bpba ligand bridging $\mathrm{Zn} 2$ and $\mathrm{Zn} 3$. The 2D structure of the framework of PUM210F is then similar to the one found in PUM210 (Figure 1b), with the two truncated SBUs being spaced only by two F-bpba ligands, along the crystallographic axis $a$.

a

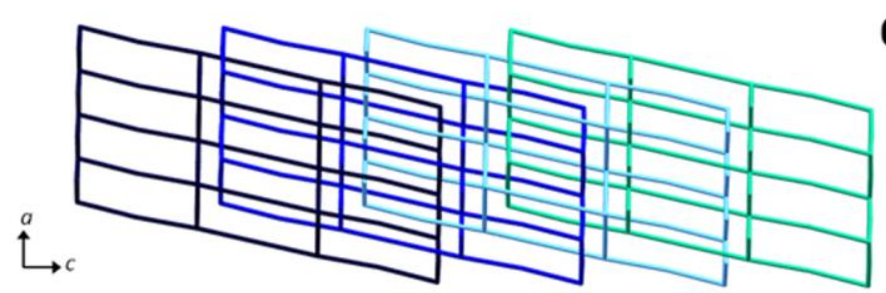

b

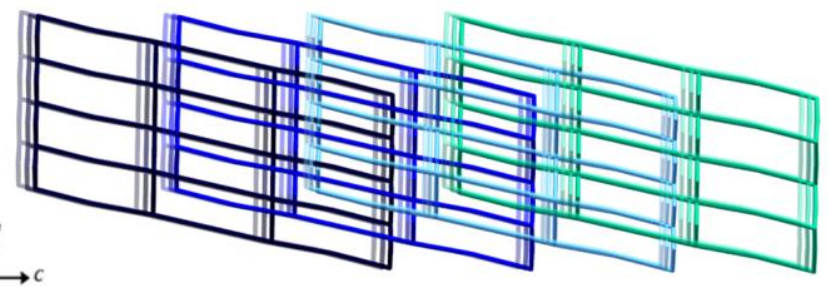

C

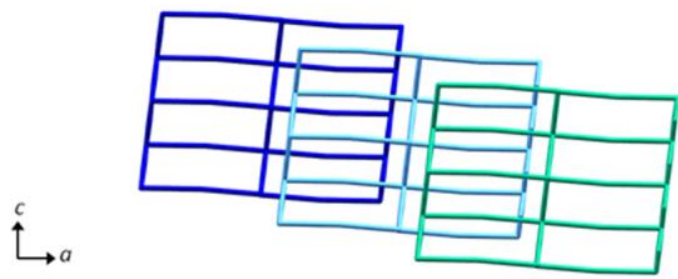

d

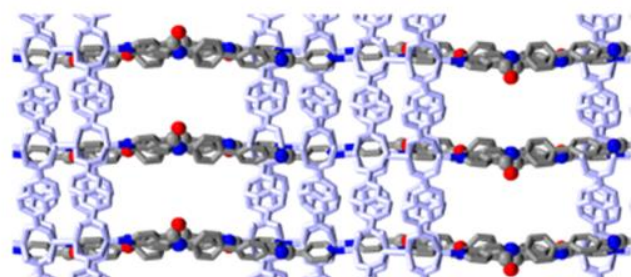

离的品 $\stackrel{b}{\hookrightarrow}$ c

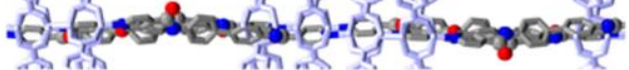

e

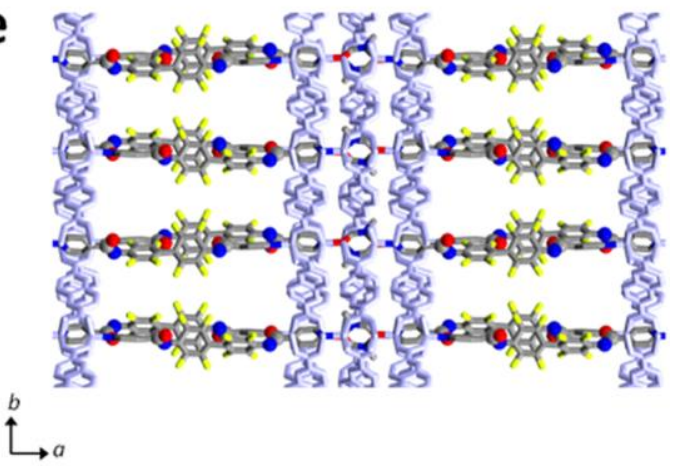


Figure 2. Simplified view of the polycatenation found in PUM210 (a) and 1D channels along crystallographic axis $a$ (d); (b) Interpretation of the structural disorder affecting PUM210 arising from networks sliding along the $c$ crystallographic direction (two additional random net positions are plotted in transparency); Simplified view of the polycatenation found in PUM210F (c) and 1D channels along crystallographic axis $c(\mathrm{e})$.

The 3D structure of PUM210 is generated by a triple polycatenation ${ }^{37}$ of parallel $2 \mathrm{D}$ nets (Figure 2a). The resultant framework displays rectangular microporous channels running along crystallographic axis $a$ (Figure $2 \mathrm{~d}, \sim 7.1 \times 11.5 \AA^{2}$ cross-section, determined including the van der Waals radius of atoms). ${ }^{38}$ As shown in Figure $2 \mathrm{~d}$, the carboxylate planes are linked by bpba linkers and the channels are decorated by amide moieties of bpba. After removal of the solvent electron density, a unit cell void volume of $37 \%$ was calculated. A similar architecture was found in PUM210F, consisting of a two-fold catenated framework (Figure 2c). The lower degree of catenation should be ascribed to the higher steric hindrance of the perfluorinated biphenyl scaffold of F-bpba, which prevents the growth of an additional net. This allows the construction of larger channels ( $~ 8.5 \times 17.2 \AA^{2}$ considering the Van der Waals radius of atoms) running along the crystallographic $c$ axis (Figure 2e). This is also reflected in a higher fraction of void volumes, once compared with PUM210, which reaches 52\% of the unit cell after removal of the solvent electron density and not considering the volume occupied by the disordered ligand. The different degree of polycatenation found in the two materials, appears to have a relevant impact on their structural flexibility. In fact, structural analyses show in both materials high electron density residuals close to the metal centres, situated along the paddlewheel axis, which is coincident with the direction of propagation of poly-catenation. These strong residues can be attributed to 
additional positions for the SBUs and, coherently, also for the linkers. The peculiar type of disorder agrees with the presence of highly correlated diffuse scattering in the diffraction patterns (see Supporting Information, section IX) and suggests that the network is capable of moving by slight sliding of the 2D sheets one on the other, as depicted in Figure $2 \mathrm{~b}$ for PUM210.

Stability. The thermal behaviour of the native MOFs was estimated by thermogravimetric analysis under nitrogen flux. TGA traces were collected using gently vacuum-dried crystals and pointed out a good thermal stability for both PUM210 and PUM210F, with $\mathrm{T}_{\mathrm{dec}}>340^{\circ} \mathrm{C}$ (Figure S5, Supporting Information). An initial two-step slope in the TGA trace of PUM210 was observed in the range $25-250^{\circ} \mathrm{C}$, corresponding to $23 \%$ weight loss. PUM210F revealed a similar behaviour with a lower weight loss, corresponding to $13 \%$, in the same interval of temperature. The amount of thermally extruded DMF molecules agreed well with the one calculated by ${ }^{1} \mathrm{H}-\mathrm{NMR}$ analyses performed on digested crystals (Figure S14, Supporting Information).

For applicative purposes, it is imperative that MOFs must be able to retain their 3D architecture even in the presence of moisture. For instance, the use of MOFs for post-combustion $\mathrm{CO}_{2}$ capture, one of the most promising applications of MOFs, is limited to those which are inert towards water. ${ }^{39-41}$ Crystals of PUM210 quickly dull and crack once removed from DMF and stored in air for a prolonged time, as usual for carboxylate-containing Zn-based MOFs. The same is true for crystals of PUM210F, although degradation is significantly slower. In both cases, complete degradation occurs once the crystals are soaked in water. The robustness of the two materials towards water was properly determined by water vapour adsorption isotherms and PXRD analysis. Before being subjected to water uptake, the crystals were activated by a solvent exchange protocol using acetone and dichloromethane, followed by high vacuum at $100^{\circ} \mathrm{C}$ 
overnight, to provide the corresponding evacuated phases (see DSC traces in Figures S10-S11). The PXRD traces of the activated phases were indicative of a substantial retention of the starting framework for PUM210, while significant structural modifications resulted evident in PUM210F. This new phase is now referred as PUM210Fa. The water vapour adsorption isotherms were determined plotting the water uptake against the relative humidity $\left(\mathrm{p} / \mathrm{p}^{\circ}\right)$ at $25^{\circ} \mathrm{C}$ (Figure S32), up to 1 bar of pressure. The resulting curves are sigmoidal, the water adsorption capacity at 1 bar being slightly higher for PUM210 than for PUM210Fa (5.71 and $4.48 \mathrm{mmol} / \mathrm{g}$, respectively). For the entire relative pressure interval investigated, the water uptake shown by PUM210 is about twice the one shown by PUM210Fa, in agreement with the higher hydrophobicity of the latter.

Transmetallation reactions: Usually, Cu-based MOFs show higher framework stability and higher $\mathrm{CO}_{2}$ uptake than Zn-based ones. ${ }^{42-46}$ Our attempts to isolate the copper analogues of PUM210 and PUM210F through direct synthesis proved to be ineffective. To overcome this limitation, we investigated the possibility of isolating the $\mathrm{Cu}$-based $\mathrm{MOF}$ through transmetalation. ${ }^{3,47}$ This approach appeared feasible, ${ }^{48}$ because the $\mathrm{Zn}$-to-Cu substitution should be favoured according to the Irving-Williams stability series. ${ }^{49}$ Moreover, in both frameworks there are SBUs containing terminal solvent species, water in the case of PUM210 and DMF in the case of PUM210F, respectively. SBUs containing labile ligands usually lead to fast transmetallation processes. ${ }^{41}$ 
a
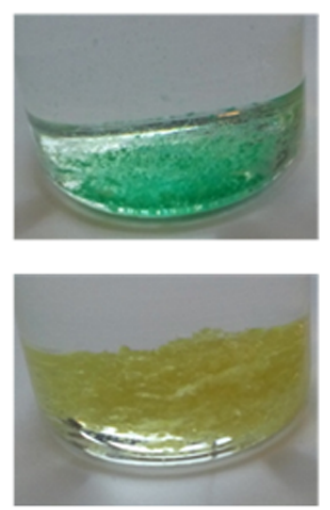

C
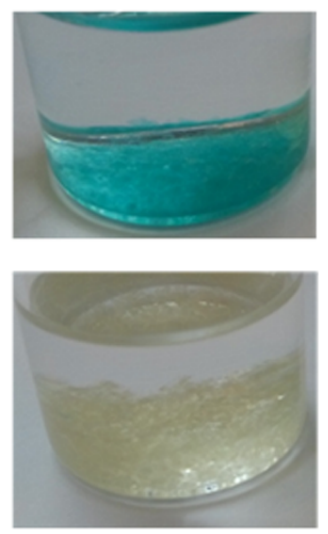

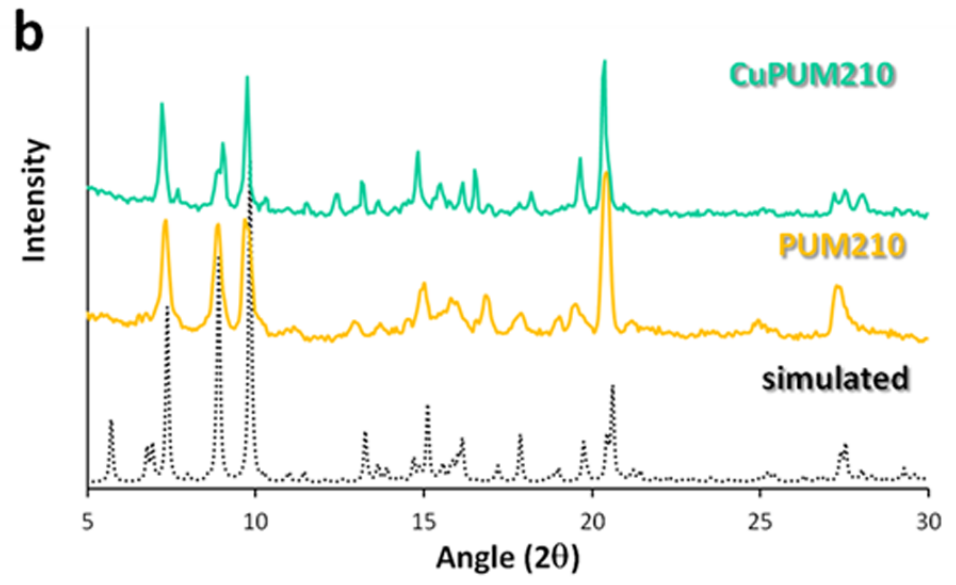

d

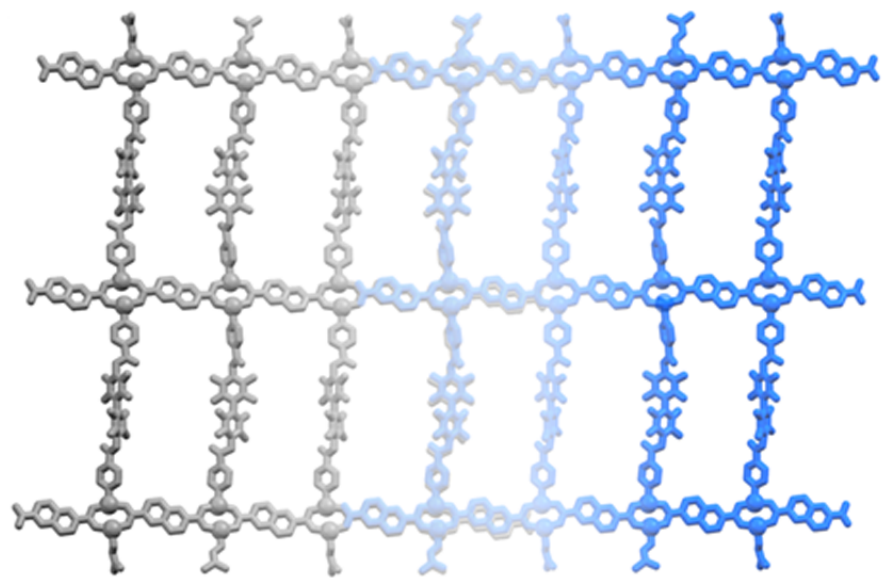

Figure 3. Chromatic variation observed during transmetallation processes of PUM210 (a) and PUM210F (c); Comparison of PXRD patterns of PUM210 (b); Superimposition of PUM210F (grey) and Cu-PUM210F (light blue) single nets, showing the retention of the framework architecture (d).

Crystals of PUM210 and PUM210F were dipped into a 0.01M DMF solution of $\mathrm{CuCl}_{2}$ thermostated at $60^{\circ} \mathrm{C}$. After three days, in both cases the occurrence of metal-exchange was indicated by a clear color change of the crystals, as inferable from Figure 3a,c. Crystals of PUM210 turned from yellow to green, while the crystals of PUM210F turned from white to turquoise. The use of $\mathrm{Cu}\left(\mathrm{NO}_{3}\right) \cdot 3 \mathrm{H}_{2} \mathrm{O}$ in place of $\mathrm{CuCl}_{2} \cdot 6 \mathrm{H}_{2} \mathrm{O}$ led to unsatisfactory results, since the color change of the crystals was much less intense after comparable reaction times. The same 
hold true carrying the reactions out at room temperature. Finally, higher copper concentrations of the transmetallating solutions or higher temperatures led to excessive fragmentation of the crystals and formation of an uncharacterized yellow side-product. Under the optimized conditions, the extent of transmetallation was established by ICP-OES (Inductively Coupled Plasma-Optical Emission Spectroscopy) analysis. After three days, in PUM210 28\% of $\mathrm{Zn}^{2+}$ exchanged with $\mathrm{Cu}^{2+}$, while in the case of PUM210F only $17 \%$ of $\mathrm{Zn}^{2+}$ exchanged. These new heterometallic materials are hereafter referred as Cu-PUM210 and Cu-PUM210F. Single crystals of Cu-PUM210 and Cu-PUM210F were subsequently picked out to be analyzed by Xray diffraction analysis to establish the occurrence of a single-crystal-to-single-crystal (SCSC) transformation. This requires that the metal-ion exchange occurs via breaking and formation of metal-ligand bonds without affecting the overall MOF architecture. A close inspection of the selected crystals by optical microscopy revealed that the crystals of Cu-PUM210F maintained their crystal habit, whereas those of Cu-PUM210 resulted damaged. Satisfactory X-ray diffraction was indeed observed only with the crystals of Cu-PUM210F. Nicely, the structural analysis revealed the retention of the starting framework, as inferable from Figure 3d, thus confirming a SCSC transformation. The asymmetric unit of Cu-PUM210F is then equivalent to that of the starting PUM210F, although in this case it was possible to model five partially occupied uncoordinated DMF molecules (see Supporting Information). The different behavior of the two types of crystals can be linked to the higher structural flexibility of the perfluorinated material conferred by the lower degree of polycatenation (double instead of triple). Noteworthy, in the F-containing framework the metal substitution had a substantial effect on the 2D networks mobility. In fact, no additional positions for the SBUs were found, thus suggesting that the polycatenated nets are now less free to slide than in the case of the starting PUM210F. 
Prolonging the soaking to 7 days led, in the case of PUM210, to excessive crystals fragmentation, phenomenon not observed in the case of PUM210F, for which the copper content reached $32 \%$.

Gas Adsorption Studies. To confirm the permanent porosity and check the $\mathrm{CO}_{2}$ uptake abilities of the porous frameworks, adsorption isotherms were collected on activated MOFs. The molecular architectures described in the previous sections allow to analyse the effect deriving from different ligand functionalization (perfluorination) and post-synthetic-modifications (partial transmetallation) onto the gas-adsorption properties of the titled pillared MOFs. The materials investigated were PUM210, PUM210F and the corresponding Cu-containing materials, CuPUM210 and Cu-PUM210F. The materials were activated following the same procedure described for the water vapour adsorption. The complete removal of the solvent molecules in the evacuated compounds was confirmed by DSC and NMR analyses (See Supporting Information). PXRD patterns evidenced structural retention passing from Cu-PUM210 to its activated phase, as inferable from Figure 3 and Figure S17, while in the case of the perfluorinated compound, noticeable structural changes appeared (see Supporting Information). This is in agreement with the higher flexibility expected for the $210 \mathrm{~F}$ series. Hereafter, this phase is referred as $\mathbf{C u}-$ PUM210Fa.

The $\mathrm{CO}_{2}$ sorption isotherms of PUM210 and PUM210Fa collected at 195K exhibited a type I Langmuir behaviour, ${ }^{50}$ indicating a favourable interaction between the amidic functionalized channels and carbon dioxide molecules during the adsorption process (Figure 4). As mentioned above, the structural modification observed after activation of PUM210F, decreases the cavity volume leading to a reduction of adsorbed gas and surface area in PUM210Fa. ${ }^{51,52}$ The experimental BET surface area calculated by $\mathrm{CO}_{2}$ isotherms resulted to be $491 \mathrm{~m}^{2} / \mathrm{g}$ and 206 
$\mathrm{m}^{2} / \mathrm{g}$ for PUM210 and PUM210Fa, respectively. In PUM210 the $\mathrm{CO}_{2}$ maximum uptake at $195 \mathrm{~K}$ corresponds to $27.1 \mathrm{wt} \%\left(138.0 \mathrm{~cm}^{3} / \mathrm{g}\right.$ and $\left.6.16 \mathrm{mmol}\right)$ while, as expected, a minor percentage of 13.9wt\% $\left(71.2 \mathrm{~cm}^{3} / \mathrm{g}\right.$ and $\left.3.16 \mathrm{mmol}\right)$ was found for PUM210Fa. The reduced adsorptive properties of the fluorinated networks could be assigned to a distortion of the $3 \mathrm{D}$ architecture during activation with a partial pore capacity reduction. ${ }^{53} \mathrm{CO}_{2}$ isotherm at $195 \mathrm{~K}$ for $\mathbf{C u}-$ PUM210Fa (Figure 4a) showed a $\sim 30 \mathrm{~cm}^{3} / \mathrm{g}$ increase in $\mathrm{CO}_{2}$ sorption capability, resulting in a surface area of $285 \mathrm{~m}^{2} / \mathrm{g}$. This improvement is linked to the robustness of the MOF caused by the presence of $\mathrm{Cu}$ ions, suggesting that the substitution of $\mathrm{Zn}$ ions with $\mathrm{Cu}$ ions is successful for increasing the adsorption properties of this family of materials. Unexpectedly, the introduction of copper does not have the same effect on PUM210, since the adsorptive capacity of Cu-PUM210 drops to $71.2 \mathrm{~cm}^{3} / \mathrm{g}$ (Figure S31), likely due to partial degradation of the crystal framework during the transmetallation process, as evidenced during the attempted SCSC transformation. Under the mild conditions of $273 \mathrm{~K}$ and $298 \mathrm{~K}$ the $\mathrm{CO}_{2}$ adsorption isotherms recorded up to 5 bar of PUM210 showed an uptake of 118.64 and $76.85 \mathrm{~cm}^{3} / \mathrm{g}$, respectively, whilst the PUM210Fa adsorbed a minor quantity in agreement with the smaller pore capacity. The isosteric heat of adsorption at low coverage obtained using Vant'Hoff equation is similar for both compounds: 27 $\mathrm{kJ} / \mathrm{mol}$ and $28 \mathrm{~kJ} / \mathrm{mol}$ for PUM210 and PUM210Fa, respectively. These values exhibited good affinity and are comparable to Zn-MOFs with a more open structure, for example Zn-MOF74. ${ }^{54}$ 


\section{a}

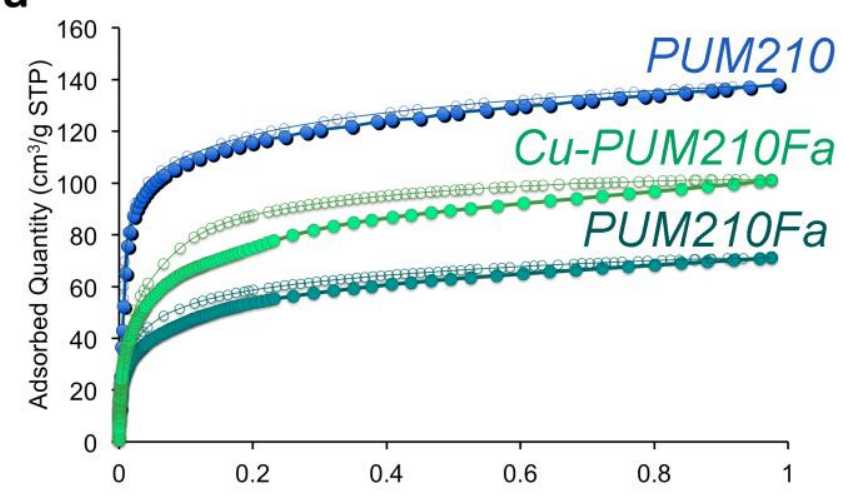

b
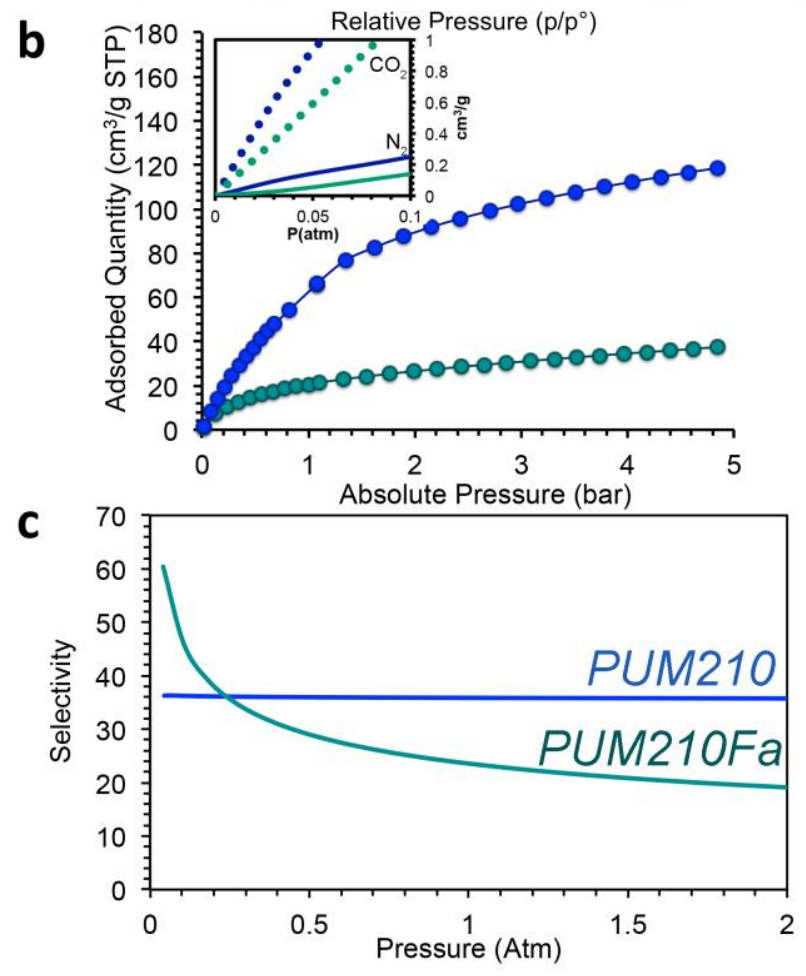

Figure 4. (a) $\mathrm{CO}_{2}$ adsorption and desorption isotherms of PUM210, PUM210Fa and CuPUM210Fa performed at $195 \mathrm{~K}$; (b) $\mathrm{CO}_{2}$ adsorption isotherms collected at $273 \mathrm{~K}$ up to 5 bar with PUM210 (blue) and PUM210Fa (green), in the inset the mixture adsorption isotherms predicted IAST of PUM210 (blue dot) and PUM210Fa (green line) for $\mathrm{CO}_{2} / \mathrm{N}_{2}$ (15/85); (c) Selectivity on a mixture of $15: 85$ of $\mathrm{CO}_{2} / \mathrm{N}_{2}$ calculated on adsorption isotherms at $273 \mathrm{~K}$ for PUM210 and PUM210Fa. 
$\mathrm{CO}_{2} / \mathrm{N}_{2}$ selectivity is of importance for $\mathrm{CO}_{2}$ purification from combustion emissions. For comparison, $\mathrm{N}_{2}$ isotherms were collected at variable temperature on PUM210 and PUM210Fa. The selectivity of $\mathrm{CO}_{2} / \mathrm{N}_{2}$ mixture (15:85) was obtained by IAST theory: at low coverage in PUM210 at 273K the selectivity was 36 (Figure 4c) while in PUM210Fa the selectivity reached the value of 60 (Figure 4c). PUM210 selectivity results to be comparable to some reported MOFs with basic functionalities in the channels, instead, PUM210Fa value is similar to MOFs with more polarized fluorine pendants in the structure. ${ }^{55,54}$ To point out the sorption features of the Zn-MOFs on environmentally important guests, methane adsorption isotherms were collected at different temperatures and up to 5 bar. The isosteric heat of adsorption resulted to be 18 $\mathrm{kJ} / \mathrm{mol}$ for PUM210 and $14 \mathrm{~kJ} / \mathrm{mol}$ for PUM210Fa, which is comparable to HKUST and MOF5 , respectively. ${ }^{56}$

\section{CONCLUSIONS}

Over decades, the classic disconnection approach employed in organic retrosynthesis has given a plenty of alternative routes to gain the desired substrate. More recently, MOFs projectability has attracted an active interest, as it could introduce the chance of combining functionalized linkers with tailored metallic secondary building units, by de-novo synthesis or through challenging PSM approaches. Herein, we have reported on the synthesis and structural characterization of novel catenated $\mathrm{Zn}^{2+}$-pillared MOFs, named PUM210 and its fluorinated analogous, PUM210F. The two frameworks are structurally similar, although the use of the perfluorinated linker F-bpba imparts peculiar features to the corresponding MOF. In fact, based on the different water adsorption isotherm profiles collected with the two MOFs, it was concluded that PUM210F is less hygroscopic than PUM210, as expected for a fluorinated MOF. Then, we have followed a transmetallation pathway in order to explore also the modification of 
the metal nodes: a convenient protocol provided the heterometallic $\mathrm{Cu}^{2+}-\mathrm{Zn}^{2+}$ derivatives $\mathbf{C u}$ PUM210 and Cu-PUM210F. The maintenance of the parent architectures was confirmed by PXRD and, notably, by SC-XRD analysis for Cu-PUM210 and Cu-PUM210F, respectively. The higher steric encumbrance of the perfluorinated biphenylene scaffold led to a lower degree of catenation, making possible the successful SCSC transformation from PUM210F to $\mathbf{C u}$ PUM210F. The activated forms of these four structurally related heteroleptic MOFs were tested for gas storage and separation. The results indicate that combination of perfluorination and transmetallation, corresponding to $\mathbf{C u}-\mathbf{P U M 2 1 0 F}$, is a convenient strategy to reach good selectivity for $\mathrm{CO}_{2}$ over $\mathrm{N}_{2}$ adsorption. Current efforts are in progress in our laboratory to extend the applied combined functionalization procedure to other PUM representatives.

\section{ASSOCIATED CONTENT}

This material is available free of charge via the Internet at http://pubs.acs.org.

General Methods, NMR and IR spectra, TGA and DSC measurements, PXRD and diffuse analysis, additional gas adsorption isotherms, selectivity and isosteric heat calculation.

CCDC 1849457-1849459 contain the supplementary crystallographic data for this paper. These data can be obtained free of charge via www.ccdc.cam.ac.uk/data_request/cif, or by emailingdata_request@ccdc.cam.ac.uk, or by contacting The Cambridge Crystallographic Data Centre, 12 Union Road,Cambridge CB2 1EZ, UK; fax: +44 1223336033.

\section{AUTHOR INFORMATION}

\section{Corresponding Author}

*paolo.pelagatti@unipr.it. 


\section{Present Addresses}

$\perp$ current affiliation: Department of Chemical Engineering, Delft University of Technology, Van der Maasweg 9, 2629 HZ, Delft, The Netherlands.

\section{Author Contributions}

The manuscript was written through contributions of all authors.

\section{ACKNOWLEDGMENT}

The authors are grateful to Monica Maffini (University of Parma) for ICP-OES measurements and Nicola Demitri (XRD1 beamline of Elettra Sincrotrone Trieste) for helpful assistance in SCXRD data collection. C.I.M. (Centro Interdipartimentale di Misure) of the University of Parma is thanked for instrument facilities. Laboratorio di Strutturistica M. Nardelli of the University of Parma is thanked for PXRD analyses. DB thanks CIRCC for research grant n. 19 (22/12/2016).

\section{REFERENCES}

(1) Slater, A. G.; Cooper, A. I. Function-Led Design of New Porous Materials. Science 2015, 348 (6238), aaa8075.

(2) Moreau, F.; Kolokolov, D. I.; Stepanov, A. G.; Easun, T. L.; Dailly, A.; Lewis, W.; Blake, A. J.; Nowell, H.; Lennox, M. J.; Besley, E.; et al. Tailoring Porosity and Rotational Dynamics in a Series of Octacarboxylate Metal-Organic Frameworks. Proc. Natl. Acad. Sci. 2017, 114 (12), 3056-3061.

(3) Lalonde, M.; Bury, W.; Karagiaridi, O.; Brown, Z.; Hupp, J. T.; Farha, O. K. Transmetalation Routes to Metal Exchange within Metal-organic Frameworks. J. Mater. Chem. A 2013, 1 (18), 5453-5468.

(4) Wang, Z.; Cohen, S. M. Postsynthetic Modification of Metal-organic Frameworks. Chem. Soc. Rev. 2009, 38 (5), 1315.

(5) Tanabe, K. K.; Cohen, S. M. Postsynthetic Modification of Metal-organic Frameworks -A Progress Report. Chem. Soc. Rev. 2011, 40 (2), 498-519.

(6) Deria, P.; Mondloch, J. E.; Karagiaridi, O.; Bury, W.; Hupp, J. T.; Farha, O. K. Beyond 
Post-Synthesis Modification: Evolution of Metal-organic Frameworks via Building Block Replacement. Chem. Soc. Rev. 2014, 43 (16), 5896-5912.

(7) Xu, Y.; Vermeulen, N. A.; Liu, Y.; Hupp, J. T.; Farha, O. K. SALE-Ing a MOF-Based "Ship of Theseus." Sequential Building-Block Replacement for Complete Reformulation of a Pillared-Paddlewheel Metal-Organic Framework. Eur. J. Inorg. Chem. 2016, 2016 (27), 4345-4348.

(8) Li, B.; Wen, H.-M.; Zhou, W.; Chen, B. Porous Metal - Organic Frameworks for Gas Storage and Separation: What, How, and Why? J. Phys. Chem. C 2014, 5, 3468-3479.

(9) Schoedel, A.; Ji, Z.; Yaghi, O. M. The Role of Metal-Organic Frameworks in a CarbonNeutral Energy Cycle. Nat. Energy 2016, 1 (4), 16034.

(10) Yu, J.; Xie, L.-H.; Li, J.-R.; Ma, Y.; Seminario, J. M.; Balbuena, P. B. CO 2 Capture and Separations Using MOFs: Computational and Experimental Studies. Chem. Rev. 2017, 117 (14), pp 9674-9754.

(11) Keskin, S.; van Heest, T. M.; Sholl, D. S. Can Metal-Organic Framework Materials Play a Useful Role in Large-Scale Carbon Dioxide Separations? ChemSusChem 2010, 3 (8), 879-891.

(12) Trickett, C. A.; Helal, A.; Al-Maythalony, B. A.; Yamani, Z. H.; Cordova, K. E.; Yaghi, O. M. The Chemistry of Metal-organic Frameworks for $\mathrm{CO}_{2}$ Capture, Regeneration and Conversion. Nat. Rev. Mater. 2017, 2 (8), 17045.

(13) Bhattacharya, B.; Ghoshal, D. Selective Carbon Dioxide Adsorption by Mixed-Ligand Porous Coordination Polymers. CrystEngComm 2015, 17 (44), 8388-8413.

(14) Vaidhyanathan, R.; Iremonger, S. S.; Shimizu, G. K. H.; Boyd, P. G.; Alavi, S.; Woo, T. K. Direct Observation and Quantification of $\mathrm{CO}_{2}$ Binding within an AmineFunctionalized Nanoporous Solid. Science 2010, 330 (6004), 650-653.

(15) Zhang, L.; Jiang, K.; Li, Y.; Zhao, D.; Yang, Y.; Cui, Y.; Chen, B.; Qian, G. Microporous Metal-Organic Framework with Exposed Amino Functional Group for High Acetylene Storage and Excellent $\mathrm{C}_{2} \mathrm{H}_{2} / \mathrm{CO}_{2}$ and $\mathrm{C}_{2} \mathrm{H}_{2} / \mathrm{CH}_{4}$ Separations. Cryst. Growth Des. 2017, 17 (5), 2319-2322.

(16) Chen, D. M.; Xu, N.; Qiu, X. H.; Cheng, P. Functionalization of Metal-Organic Framework via Mixed-Ligand Strategy for Selective $\mathrm{CO}_{2}$ Sorption at Ambient Conditions. Cryst. Growth Des. 2015, 15 (2), 961-965.

(17) Lee, C.; Huang, H.; Liu, Y.; Luo, T.; Lee, G.; Peng, S.; Jiang, J.; Chao, I.; Lu, K. Cooperative Effect of Unsheltered Amide Groups on CO 2 Adsorption Inside Open-Ended Channels of a Zinc(II) - Organic Framework,. Inorg. Chem. 2013, 52 (7), 3962-3968. (18) Safarifard, V.; Rodríguez-Hermida, S.; Guillerm, V.; Imaz, I.; Bigdeli, M.; Tehrani, A. A.; Juanhuix, J.; Morsali, A.; Casco, M. E.; Silvestre-Albero, J.; et al. Influence of the Amide Groups in the CO2/N2 Selectivity of a Series of Isoreticular, 
Interpenetrated Metal-Organic Frameworks. Cryst. Growth Des. 2016, 16 (10), 60166023.

(19) Alsmail, N. H.; Suyetin, M.; Yan, Y.; Cabot, R.; Krap, C. P.; Lü, J.; Easun, T. L.; Bichoutskaia, E.; Lewis, W.; Blake, A. J.; et al. Analysis of High and Selective Uptake of $\mathrm{CO}_{2}$ in an Oxamide-Containing $\left\{\mathrm{Cu}_{2}(\mathrm{OOCR})_{4}\right\}$-Based Metal-Organic Framework. Chem. - A Eur. J. 2014, 20 (24), 7317-7324.

(20) Zheng, B.; Bai, J.; Duan, J.; Wojtas, L.; Zaworotko, M. J. Enhanced $\mathrm{CO}_{2}$ Binding Affinity of a High-Uptake Rht-Type Metal-Organic Framework Decorated with Acylamide Groups. J. Am. Chem. Soc. 2011, 133 (4), 748-751.

(21) Bent, H. A. Structural Chemistry of Donor-Acceptor Interactions. Chem. Rev. 1968, 68 (5), 587-648.

(22) Zhang, D.-S.; Chang, Z.; Li, Y.-F.; Jiang, Z.-Y.; Xuan, Z.-H.; Zhang, Y.-H.; Li, J.-R.; Chen, Q.; Hu, T.-L.; Bu, X.-H. Fluorous Metal-Organic Frameworks with Enhanced Stability and High $\mathrm{H}_{2} / \mathrm{CO}_{2}$ Storage Capacities. Sci. Rep. 2013, 3 (1), 3312.

(23) Chen, T.-H.; Popov, I.; Zenasni, O.; Daugulis, O.; Miljanić, O. Š. Superhydrophobic Perfluorinated Metal-organic Frameworks. Chem. Commun. 2013, 49 (61), 6846.

(24) Chen, C. X.; Wei, Z. W.; Qiu, Q. F.; Fan, Y. Z.; Cao, C. C.; Wang, H. P.; Jiang, J. J.; Fenske, D.; Su, C. Y. A Porous Zn(II)-Metal-Organic Framework Constructed from Fluorinated Ligands for Gas Adsorption. Cryst. Growth Des. 2017, 17 (4), 1476-1479.

(25) Pachfule, P.; Das, R.; Poddar, P.; Banerjee, R. Structural, Magnetic, and Gas Adsorption Study of a Series of Partially Fluorinated Metal-Organic Frameworks (HF-MOFs). Inorg. Chem. 2011, 50 (Scheme 1), 3855-3865.

(26) Luo, X.; Yin, Z.; Zeng, M.; Kurmoo, M. The Construction, Structures, and Functions of Pillared Layer Metal-Organic Frameworks. Inorg. Chem. Front. 2016, 3, 1208-1226.

(27) Huang, S. L.; Lin, Y. J.; Li, Z. H.; Jin, G. X. Self-Assembly of Molecular Borromean Rings from Bimetallic Coordination Rectangles. Angew. Chemie - Int. Ed. 2014, 53 (42), $11218-11222$.

(28) Davide Balestri, Davide Costa, Alessia Bacchi, Lucia Carlucci, P. P. Linker Dependent Dimensionality in Zn(II)-Coordination Polymers Containing a Flexible Bis-Pyridyl-BisAmide Ligand. Polyhedron-submitted

(29) Balestri, D.; Bacchi, A.; Scilabra, P.; Pelagatti, P. Extension of the Pd-Catalyzed CN Bond Forming Reaction to the Synthesis of Large Polydentate Ligands Containing NH Functions. Inorganica Chim. Acta 2017, 470, 416-422.

(30) Lausi, A.; Polentarutti, M.; Onesti, S.; Plaisier, J.R.; Busetto, E.; Bais, G.; Barba, L.; Cassetta, A.; Campi, G.; Lamba, D. Status of the Crystallography Beamline at Elettra. Eur. Phys. J. Plus 2015, 130, 1-8. 
(31) Sheldrick, G. M. A Short History of SHELX. Acta Crystallogr. Sect. A Found. Crystallogr. 2007, 64 (1), 112-122.

(32) Dolomanov, O. V.; Bourhis, L. J.; Gildea, R. J.; Howard, J. A. K.; Puschmann, H. OLEX2: A Complete Structure Solution, Refinement and Analysis Program. J. Appl. Crystallogr. 2009, 42 (2), 339-341.

(33) Köberl, M.; Cokoja, M.; Herrmann, W. A.; Kühn, F. E. From Molecules to Materials: Molecular Paddle-Wheel Synthons of Macromolecules, Cage Compounds and MetalOrganic Frameworks. Dalt. Trans. 2011, 40 (26), 6834-6859.

(34) Wang, S.; Xiong, S.; Wang, Z.; Du, J. Rational Design of Zinc-Organic Coordination Polymers Directed by N-Donor Co-Ligands. Chem. - A Eur. J. 2011, 17 (31), 8630-8642.

(35) Chun, H.; Jung, H.; Seo, J. Isoreticular Metal-Organic Polyhedral Networks Based on 5Connecting Paddlewheel Motifs. Inorg. Chem. 2009, 48 (5), 2043-2047.

(36) Chun, H. Low-Level Self-Assembly of Open Framework Based on Three Different Polyhedra: Metal-Organic Analogue of Face-Centered Cubic Dodecaboride. J. Am. Chem. Soc. 2008, 130 (3), 800-801.

(37) Carlucci, L.; Ciani, G.; Proserpio, D. M. Polycatenation, Polythreading and Polyknotting in Coordination Network Chemistry. Coord. Chem. Rev. 2003, 246 (1-2), 247-289.

(38) Batsanov, S. S. Van Der Waals Radii of Elements. Inorg. Mater. Transl. from Neorg. Mater. Orig. Russ. Text 2001, 37 (9), 871-885.

(39) Furukawa, H.; Ga, F.; Hudson, M. R.; Yaghi, O. M. Water Adsorption in Porous Metal Organic Frameworks and Related Materials. J. Am. Chem. Soc. 2014, 136(11), 4369-4381

(40) Wang, C.; Liu, X.; Keser Demir, N.; Chen, J. P.; Li, K. Applications of Water Stable Metal-organic Frameworks. Chem. Soc. Rev. 2016, 45 (18), 5107-5134.

(41) Canivet, J.; Fateeva, A.; Guo, Y.; Coasne, B.; Farrusseng, D. Water Adsorption in MOFs: Fundamentals and Applications. Chem. Soc. Rev. 2014, 43 (16), 5594-5617.

(42) Song, X.; Jeong, S.; Kim, D.; Lah, M. S. Transmetalations in Two Metal-organic Frameworks with Different Framework Flexibilities: Kinetics and Core-shell Heterostructure. CrystEngComm 2012, 14 (18), 5753.

(43) Pal, T. K.; De, D.; Neogi, S.; Pachfule, P.; Senthilkumar, S.; Xu, Q.; Bharadwaj, P. K. Significant Gas Adsorption and Catalytic Performance by a Robust CuII-MOF Derived through Single-Crystal to Single-Crystal Transmetalation of a Thermally Less-Stable ZnII-MOF. Chem. - A Eur. J. 2015, 21 (52), 19064-19070.

(44) Xiao, Z.; Wang, Y.; Zhang, S.; Fan, W.; Xin, X.; Pan, X.; Zhang, L.; Sun, D. Stepwise Synthesis of Diverse Isomer MOFs via Metal-Ion Metathesis in a Controlled SingleCrystal-to-Single-Crystal Transformation Cryst. Growth Des. 2017, 17 (8), 4084-4089. 
(45) Yang, J.; Wang, X.; Dai, F.; Zhang, L.; Wang, R.; Sun, D. Improving the Porosity and Catalytic Capacity of a Zinc Paddlewheel Metal-Organic Framework (MOF) through Metal-Ion Metathesis in a Single-Crystal-to-Single-Crystal Fashion. Inorg. Chem. 2014, 53 (19), 10649-10653.

(46) Pal, T. K.; De, D.; Senthilkumar, S.; Neogi, S.; Bharadwaj, P. K. A Partially Fluorinated, Water-Stable $\mathrm{Cu}$ (II)-MOF Derived via Transmetalation: Significant Gas Adsorption with High CO2 Selectivity and Catalysis of Biginelli Reactions. Inorg. Chem. 2016, 55 (16), 7835-7842.

(47) Brozek, C. K.; Dincă, M. Cation Exchange at the Secondary Building Units of MetalOrganic Frameworks. Chem. Soc. Rev. 2014, 43, 5456-5467.

(48) Pal, T. K.; Neogi, S.; Bharadwaj, P. K. Versatile Tailoring of Paddle-Wheel ZnII MetalOrganic Frameworks through Single-Crystal-to-Single-Crystal Transformations. Chem. A Eur. J. 2015, 21 (45), 16083-16090.

(49) Deria, P.; Mondloch, J. E.; Karagiaridi, O.; Bury, W.; Hupp, J. T.; Farha, O. K. Beyond Post-Synthesis Modification: Evolution of Metal-organic Frameworks via Building Block Replacement. Chem. Soc. Rev. Chem. Soc. Rev 2014, 5896 (43), 5896-5912.

(50) Brunauer, S.; Deming, L. S.; Deming, W. E.; Teller, E. On a Theory of the van Der Waals Adsorption of Gases. J. Am. Chem. Soc. 1940, 62 (7), 1723-1732.

(51) Chang, G.; Wen, H.; Li, B.; Zhou, W.; Wang, H.; Alfooty, K.; Bao, Z.; Chen, B. A Fluorinated Metal-Organic Framework for High Methane Storage at Room Temperature. Cryst. Growth Des. 2016, 16 (6), 3395-3399.

(52) Chang, ganggang; Li, B.; Wang, H.; Bao, Z.; Yildirim, T.; Yao, Z.-Z.; Xiang, S.; Zhou, W.; Chen, B. A Microporous Metal-organic Framework with Polarized Trifluoromethyl Groups for High Methane Storage. Chem. Commun. 2015, 51, 14789-14792.

(53) Bureekaew, S.; Sato, H.; Matsuda, R.; Kubota, Y.; Hirose, R.; Kim, J.; Kato, K.; Takata, M.; Kitagawa, S. Control of Interpenetration for Tuning Structural Flexibility Influences Sorption Properties. Angew. Chemie - Int. Ed. 2010, 49 (42), 7660-7664.

(54) Queen, W. L.; Hudson, M. R.; Bloch, E. D.; Mason, J. A.; Gonzalez, M. I.; Lee, J. S.; Gygi, D.; Howe, J. D.; Lee, K.; Darwish, T. A.; et al. Comprehensive Study of Carbon Dioxide Adsorption in the Metal-organic Frameworks $\mathrm{M}_{2}$ (Dobdc) $(\mathrm{M}=\mathrm{Mg}, \mathrm{Mn}, \mathrm{Fe}$, Co, Ni, Cu, Zn). Chem. Sci. 2014, 5 (12), 4569-4581.

(55) Zhang, Z.; Yao, Z.-Z.; Xiang, S.; Chen, B. Perspective of Microporous Metal-organic Frameworks for $\mathrm{CO}_{2}$ Capture and Separation. Energy Environ. Sci. 2014, 7 (9), 2868.

(56) Mason, J. A.; Veenstra, M.; Long, J. R. Evaluating Metal-organic Frameworks for Natural Gas Storage. Chem. Sci. 2014, 5 (1), 32-51. 
SYNOPSIS The structural and gas-sorption effects deriving from ligand perfluoruration and partial transmetallation have been evaluated for a series of structurally related pillared MOFs

\section{FOR TABLE OF CONTENTS ONLY}

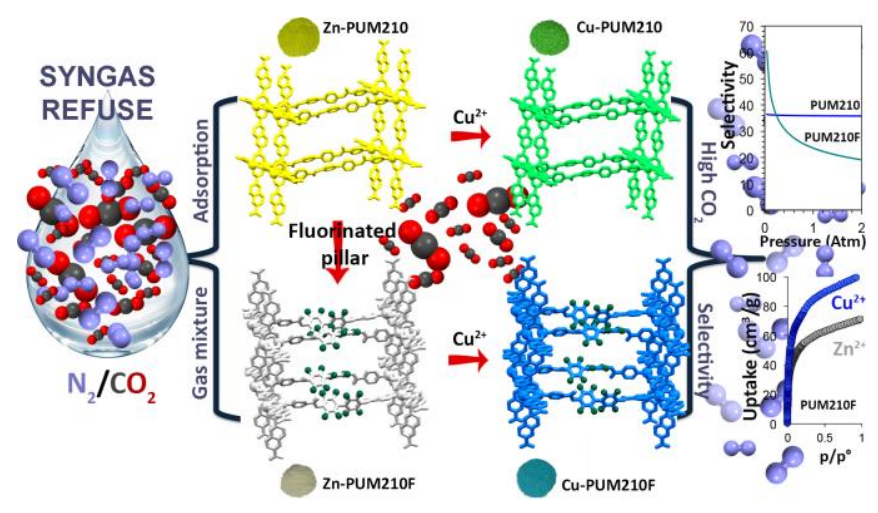

